\title{
Modeling of the Financial System Using the Concept of Vacuum Polarization
}

\author{
Dmitry Alexandrovich Shustov \\ Dep. of computer science, modeling and \\ human sciences \\ Financial University under the Gov- \\ ernment of the Russian Federation, St. \\ Petersburg branch \\ St. Petersburg \\ Russia \\ dim_shu@mail.ru
}

\author{
Mikhail Yuryevich Volokobinsky \\ Dep. of computer science, modeling and \\ human sciences \\ Financial University under the Gov- \\ ernment of the Russian Federation, St. \\ Petersburg branch \\ St. Petersburg \\ Russia \\ volokobin@mail.ru
}

\author{
Olga Anatolyevna Pekarskaya \\ Dep. of computer science, modeling and \\ human sciences \\ Financial University under the Gov- \\ ernment of the Russian Federation, St. \\ Petersburg branch \\ St. Petersburg \\ Russia \\ pekarskaya.olga@mail.ru
}

\begin{abstract}
The possibility of using the theory of deterministic chaos is considered. Vacuum polarization is a fundamental type of physical processes. The average value of any physical quantity must remain zero. Taking this assumption as a fundamental law, we propose a model that describes the processes of variation (depreciation) of the value of money. At the same time, we consider the processes of variation of the initial amount of funds introduced into the economic system by an independent "generator" (for example, the US Federal Reserve System) in a situation when the amount of returned funds must exceed the amount of given credits. Since the amount of returned funds must exceed the amount borrowed by the value of the refinancing rate, either a constantly increasing debt is formed, or an increase in the money introduced to the economy. The relationship of the "depreciation" of money is also investigated in this model
\end{abstract}

Keywords-cash, depreciation, financial system, model, regularities, trends.

\section{INTRODUCTION}

The existence of various macroeconomic schools: classicism, Keynesianism, monetarism, reflect, at a minimum, the complexity of the formation of a model of an economic system.

In different models, the role and patterns of monetary circulation are determined differently. In particular, the model of circulation of money and

inflation is formed in different ways. At different historical stages, these models turn out to be untenable.

Taking into account that the economic system represented as the social practice of people under the division of labour and the existence of property rights to the results of labour, aimed to satisfy the needs and based on the equivalence (determination of the equivalent) of exchange processes, money initially acts as an equivalent, and are essentially models of these processes.

It is logical to assume that socio-economic systems, as a part of the surrounding world, are subject to general objective physical laws. In particular, the fundamental type of physical processes - vacuum polarization - can serve as the basis for modelling monetary circulation in socio-economic systems.

The starting point of the work is the assumption that socio-economic systems, as a part of the surrounding world, obey the universal objective physical laws. In particular, the fundamental type of physical processes vacuum polarization - can serve as the basis for modeling the properties of socio-economic systems.

In accordance with this type, the average value of any physical quantity must remain zero (constant, by changing the reference point may be reduced to zero).

This approach is well known in physics in various formulations, such as, for example, the law of conservation of matter, the law of conservation of energy $[2,3]$.

The aim of this work is to develop a model of money circulation, using the concept of vacuum polarization: money is generated artificially as the equivalent of goods and services produced by the economy, and cyclically "returns" to the generator.

\section{Materials And Methods}

When modelling the economic system, the subject of research in this study is the patterns of change in the monetary equivalent of labour results and needs that are satisfied in the course of practical activity of people in market economy.

\section{Research Methods - Mathematical Modelling.}

Since at present time money circulation is determined by an independent participant (regulator) of economic systems (for example, the US Federal Reserve System), which credits all economic activity, funding money according to the conditions of returning of greater amount of money than taken on credit, by the value of the lending rate . 
In such a situation, to simulate the process of cash flow in the economy, taking into account the fundamental property of vacuum polarization, the following prerequisites (axioms) must be fulfilled:

1. The number of participants satisfying their needs is constant.

2. The amount of money given on credit is allocated at the beginning of the period and does not change over the period of one cycle (usually a year)

3. Money, as an exchange equivalent, is returned to an independent regulator.

4. The average price of economic transactions is defined as the quotient of the division of cash volume in the economy, divided by the number of participants in the economic system.

5. Since the economy does not have additional physically existing funds needed to repay the cost of the loan, they are taken as a new loan in the next step.

\section{RESULTS}

It is quite obvious that the model describes the properties of a dynamic system that may be described in phase space [4], [5] with the help of a system of differential equations:

$$
\frac{d \boldsymbol{X}}{d t}=\boldsymbol{F}(\boldsymbol{x})
$$

In our case it is a discrete system:

$$
\frac{x}{t}=F(x)
$$

where $\Delta \mathrm{x}$ is the change in $\mathrm{x}$ over a period of time $\Delta \mathrm{t}$.

At a formalized level, the model is as follows:

Oi - the amount of money contributed to the economy in the form of a loan (for example, the Fed printed \$ $1,000,000$ for $i=1$ first period)

Sti - lending rate (for example, $10 \%$ for $\mathrm{i}=1$ period)

WPi - received proceeds from the sale for $\mathrm{i}$-th period (must be equal to the amount of money received from the Regulator)

Koli - the number of participants on the i-th period.

Cenai is the price of purchased goods and services for the i-th period reduced to one participant. Price is determined by the ratio:

$$
\text { Cena }_{i}=\frac{o_{i}}{\text { Kol }_{i}}
$$

Dolgi - creditors debt not secured by cash available in the economy on the i-th period

Infli - the absolute value of the "depreciation" of money (relative to the first period) on the i-th period:

$$
\text { Infl } l_{i}=\frac{\left(\frac{W P_{i}\left(1+S t_{i}\right)}{\text { Kol }_{i}}\right)}{\text { Cena }_{1}} \quad 1
$$

Year $_{\text {ihf }}$ is the depreciation value relative to the previous period:

$$
\operatorname{Year}_{i n f}=\operatorname{Infl} l_{i} \quad \operatorname{Inf} l_{i-1}
$$

For $\mathrm{i}>1$

Then the solution of equation (2) can be obtained in tabular form, using the EXCEL processor.

A fragment of the calculation is shown in Fig. 1.

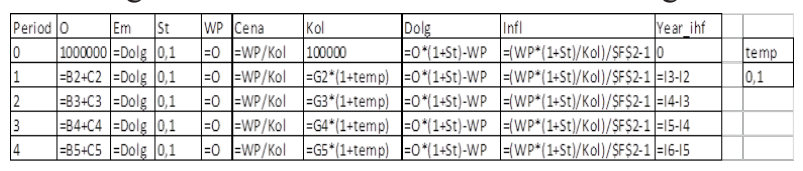

Fig. 1. Fragment of tabular model with calculation formulas

In the tabular model, the additional variable WPi is used to give a probability for further investigation of the influence of additional factors.

The variable "temp" allows to include an additional factor in the model - the share of the increment of system participants (market growth rate).

At the first stage the situation, when the market volume is assumed to be constant, lending is introduced "at one time" at the beginning of the period, loan repayment is carried out "at one time" - at the periods" end, is modeled.

To return the interest on the loan at the end of the period, additional funds are issued in the amount of the refinancing rate, which are given in the form of an increase of credit volumes.

\section{Interest Rate does not change.}

For example, with the initial amount of cash in the amount of $\$ 1,000,000$ at $10 \%$ per annum for one year, introduced into the economic system where the number of participants is equal to 100,000 , in one year it will be necessary to return to the Regulator $\$ 1,100,000$, but only $1,000,000$ is practically available. That is that during the next year it will be necessary to "reprint" (emmit) an additional \$100,000 into the economy.

But one year later it will be necessary to return 1121 000 \$, etc.

The data fragment and the graph of "depreciation" of funds by periods is shown in Fig. 2.

\begin{tabular}{|r|r|l|r|l|r|l|l|r|r|}
\hline Perio & 0 & Em & St & WP & Cena & Kol & Dolg & Infl & Year_inf \\
\hline 0 & 1000000 & 100000 & $10,00 \%$ & 1000000 & 10 & 100000 & 100000 & $0,00 \%$ & $0,00 \%$ \\
\hline 1 & 1100000 & 110000 & $10,00 \%$ & 1100000 & 11 & 100000 & 110000 & $10,00 \%$ & $10,00 \%$ \\
\hline 2 & 1210000 & 121000 & $10,00 \%$ & 1210000 & 12,1 & 100000 & 121000 & $21,00 \%$ & $11,00 \%$ \\
\hline 3 & 1331000 & 133100 & $10,00 \%$ & 1331000 & 13,3 & 100000 & 133100 & $33,10 \%$ & $12,10 \%$ \\
\hline 4 & 1464100 & 146410 & $10,00 \%$ & 1464100 & 14,6 & 100000 & 146410 & $46,41 \%$ & $13,31 \%$ \\
\hline 5 & 1610510 & 161051 & $10,00 \%$ & 1610510 & 16,1 & 100000 & 161051 & $61,05 \%$ & $14,64 \%$ \\
\hline 6 & 1771561 & 177156 & $10,00 \%$ & 1771561 & 17,7 & 100000 & 177156 & $77,16 \%$ & $16,11 \%$ \\
\hline 7 & 1948717,1 & 194872 & $10,00 \%$ & 1948717 & 19,5 & 100000 & 194872 & $94,87 \%$ & $17,72 \%$ \\
\hline 8 & 2143588,8 & 214359 & $10,00 \%$ & 2143589 & 21,4 & 100000 & 214359 & $114,36 \%$ & $19,49 \%$ \\
\hline 9 & 2357947,7 & 235795 & $10,00 \%$ & 2357948 & 23,6 & 100000 & 235795 & $135,79 \%$ & $21,44 \%$ \\
\hline 10 & 2593742,5 & 259374 & $10,00 \%$ & 2593742 & 25,9 & 100000 & 259374 & $159,37 \%$ & $23,58 \%$ \\
\hline 11 & 2853116,7 & 285312 & $10,00 \%$ & 2853117 & 28,5 & 100000 & 285312 & $185,31 \%$ & $25,94 \%$ \\
\hline 12 & 3138428,4 & 313843 & $10,00 \%$ & 3138428 & 31,4 & 100000 & 313843 & $213,84 \%$ & $28,53 \%$ \\
\hline 13 & 3452271,2 & 345227 & $10,00 \%$ & 3452271 & 34,5 & 100000 & 345227 & $245,23 \%$ & $31,38 \%$ \\
\hline 14 & 3797498,3 & 379750 & $10,00 \%$ & 3797498 & 38 & 100000 & 379750 & $279,75 \%$ & $34,52 \%$ \\
\hline 15 & 4177248,2 & 417725 & $10,00 \%$ & 4177248 & 41,8 & 100000 & 417725 & $317,72 \%$ & $37,97 \%$ \\
\hline 16 & 4594973 & 459497 & $10,00 \%$ & 4594973 & 45,9 & 100000 & 459497 & $359,50 \%$ & $41,77 \%$ \\
\hline 17 & 5054470,3 & 505447 & $10,00 \%$ & 5054470 & 50,5 & 100000 & 505447 & $405,45 \%$ & $45,95 \%$ \\
\hline 18 & 5559917,3 & 555992 & $10,00 \%$ & 5559917 & 55,6 & 100000 & 555992 & $455,99 \%$ & $50,54 \%$ \\
\hline 19 & 6115909 & 611591 & $10,00 \%$ & 6115909 & 61,2 & 100000 & 611591 & $511,59 \%$ & $55,60 \%$ \\
\hline 20 & 6727499,9 & 672750 & $10,00 \%$ & 6727500 & 67,3 & 100000 & 672750 & $572,75 \%$ & $61,16 \%$ \\
\hline 21 & 7400249,9 & 740025 & $10,00 \%$ & 7400250 & 74 & 100000 & 740025 & $640,02 \%$ & $67,27 \%$ \\
\hline 22 & 8140274,9 & 814027 & $10,00 \%$ & 8140275 & 81,4 & 100000 & 814027 & $714,03 \%$ & $74,00 \%$ \\
\hline 23 & 8954302,4 & 895430 & $10,00 \%$ & 8954302 & 89,5 & 100000 & 895430 & $795,43 \%$ & $81,40 \%$ \\
\hline
\end{tabular}

(a) 


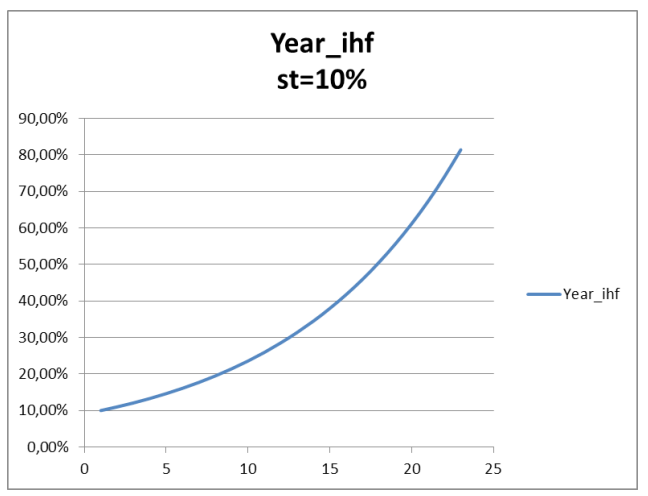

(b)

Fig. 2 Tabular model and schedule "depreciation"

Obvious is the conclusion about the increase in the rate of "depreciation" of funds, ahead of the refinancing rate.

If the number of participants in the economy increases (the model takes into account discrete - over the years increase in the market) in an amount not exceeding the refinancing rate, the cash depreciation will decrease to zero. A number of graphs for the values of growth rates of $5 \%$ and $8 \%$ are shown in Fig. 3 .

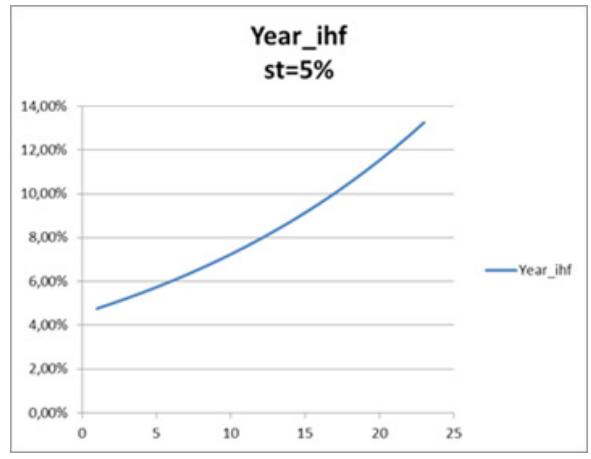

(a)

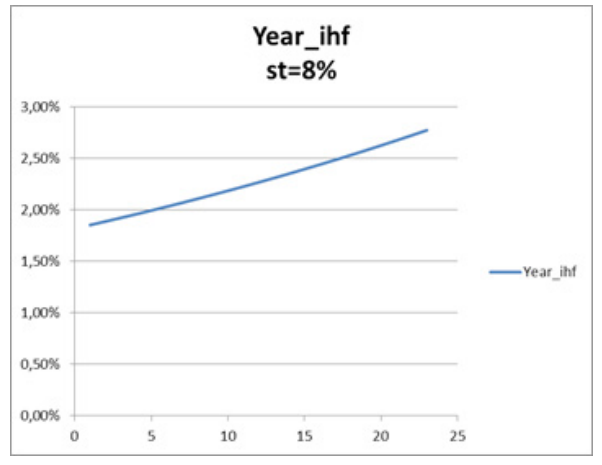

(b)

Fig. 3 Schedule of "depreciation" for the market growth rate of $5 \%$ and $8 \%$

As we see, the rate of "depreciation" decreases from $80 \%$ up to 14 and 2.8 , respectively.

Let's build a model of cash depreciation on the basis of statistical data on the Fed's refinancing rates and data on US inflation over the past 20 years [4], [5].

The simulation results are shown in Fig.4

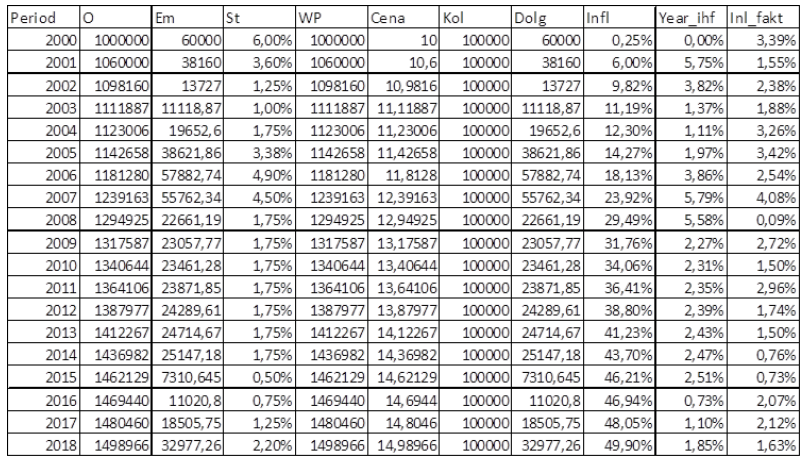

(a)

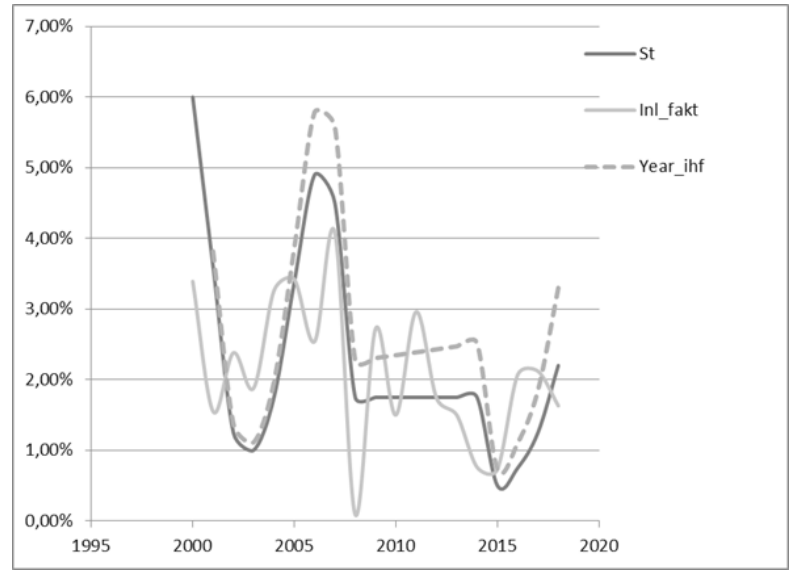

(b)

Fig. 4. Simulation results with real Fed rates for the period 2000-2018.

The simulation results show the principal workability of the model, despite of the difference in the prerequisites - a real increase in total dollars (national debt) does not allow to accept as constant the volume of domestic market. However, modelling according to the US Federal Reserve for inflation and comparison with the limited market model shows comparable results in terms of trends, since the growth of the US market is due to the expense of other countries financed by the Fed, therefore the US market itself can be assumed as "limited".

\section{Confirmation}

Correlation analysis of data on inflation and refinancing rates of the USA over the past 18 years allows us to estimate the existence of a linear relationship between sets of values of random variables.

Since the value of the refinancing rate and the inflation value for the simulated period may be considered as random variables, the analysis of the existence of a linear relationship between the real rate (Sti) and the value of the money depreciation Year_ihf was undertaken. The results of the analysis performed in EXCEL are shown in Fig. 5. 


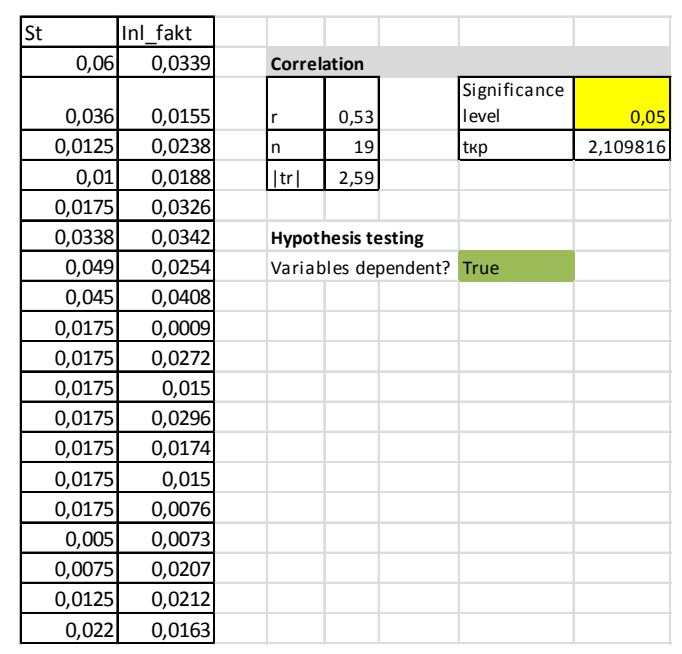

Fig. 5. Simulation results with

Comparing the values of t-statistics with a critical value allows us to state a linear relationship between the refinancing rate and the inflation rate based on official data [6], [7]

\section{Conclusions}

A currency circulation model based on the concept of vacuum polarization has been developed and implemented.

The study of the model confirms the existence of a link between "depreciation" and the value of the interest rate of the regulator's lending.

The results of implementation of the model with real US FRS refinancing rates during 18 years showed a correlation between the Fed rate and the inflation rate, which allows us to make a conclusion that the model works in principle.

It is important to underline that this model can be used to study the effect on the "depreciation" of funds of other important factors, such as expansion and market contraction (change in the number of participants), withdrawal of funds from economy (decrease in the amount of funds)

It should be noted that the rate of inflation, calculated in a number of countries using different methods, may not correlate with the "depreciation" of money, caused by the principal parameter - the value of the refinancing rate.

\section{REFERENCES}

[1] E. J. Dolan et al.. Money, banking and monetary policy / Per. with English. V. Lukashevich, etc.; under the General ed.- Moscow, -448.. 1996 Available: https://economy24info.com/kredit-obraschenie-denejnoe/dengi-bankovskoe-delo-denejno-kreditnaya.html

[2] . S. P. Kuznetsov Dynamical chaos and hyperbolic attractors. From mathematics to physics - Moscow, Izhevsk: Regular and chaotic dynamics, Izhevsk Institute of computer research, 2013.488 c. - Available: http://www.iprbookshop.ru/28886.html

[3] M.B. Ignat'ev Kiberneticheskaja kartina mira. Slozhnye kiberfizicheskie sistemy [Cybernetic picture of the world. Complex cyber-physical systems]. St. Petersburg, SUAI Publ; 2014. 472 p.

[4] M. B. Ignat'ev ; A. E. Karlik ; E. A. Iakovleva ; V. V. Platonov Linguo-Combinatorial Model for Diagnosing the State of Human Resources in the Digital Economy 2018 XVII Russian Scientific and Practical Conference on Planning and Teaching Engineering Staff for the Industrial and Economic Complex of the Region (PTES) https://ieeexplore.ieee.org/document/8604217

[5] D. A. Shustov. The possibilities of using the linguo-combinatorial approach in the modeling of economic processes. Information-Communication-Society (ICO-2019): Proceedings of the XVI all-Russian scientific conference / St. Petersburg, $24-25$ January 2019.: Publishing house of Etu, 2019. - Vol. 1. P. 390-394

[6] Reference materials $>$ inflation $>$ US Inflation Rate Federal reserve: 2000 - 2019, http://global-finances.ru/stavka-frs-ssha, [Accessed March 27, 2019

[7] World Finance. Inflation in the US, https://fin-plus.ru/info/inflation_index/usa/, [Accessed March 27, 2019 